\title{
The antimicrobial activity of probiotic bacteria Escherichia coli isolated from different natural sources against hemorrhagic $E$. coli O157:H7
}

Sahar Karimi ${ }^{1}$, Fatemeh Azizi ${ }^{1}$, Mohammad Nayeb-Aghaee ${ }^{2}$, Leila Mahmoodnia ${ }^{3}$

${ }^{1}$ M.Sc. of Microbiology, Department of Biology, Faculty of Science, Shahid Chamran University of Ahvaz, Iran

${ }^{2}$ M.Sc. of Bacteriology, Faculty of Veterinary Medicine, Lorestan University, Iran

${ }^{3}$ Nephrology Fellowship, Department of Internal Medicine, Shahrekord University of Medical Sciences, Shahrekord, Iran

\section{Type of article: Original}

\begin{abstract}
Background: Diarrheal diseases have been seen in all geographical areas throughout the world. Therefore, considering treatment, could be deemed a necessary action.

Objective: The aim of this study was to determine the antimicrobial effect of probiotic bacterial strains isolated from different natural sources against 2 pathotypes of pathogenic E. coli.

Methods: This cross-sectional study of Martyr Chamran University of Ahvaz was carried out from December 2013 to July 2014. A total of 13 probiotic colonies isolated from 20 samples of traditional dairy products including (yogurt, cheese, milk) and 20 samples of vegetables including carrots and cabbages (red and white) of which 5 isolates were selected to evaluate the antimicrobial effect against 2 Escherichia coli pathotypes, randomly. Antimicrobial effect was evaluated using two methods: disk diffusion and well diffusion tests and measuring growth inhibition zones of probiotics against 2 pathotypes of pathogenic E. coli.

Results: Obtained results showed growth inhibition effects of all 5 probiotic strains against Escherichia coli pathotypes in both used methods. All selected strains showed considerable antimicrobial effect on Escherichia coli O157:H7 strain, but had no inhibitory effect against Enterohemorrhagic Escherichia coli.

Conclusion: This study demonstrated considerable antimicrobial effect against E. coli O157:H7 strain. Due to this, characteristic and similar antimicrobial effects of probiotics bacteria, increasing use of the probiotics as a natural and modern method for prevention of different diseases is recommended.
\end{abstract}

Keywords: Probiotics, Enteropathogenesis, Enterohemorrhagic Escherichia coli, Escherichia coli O157:H7

\section{Introduction}

Probiotics are special microorganisms with important characteristics. They can tolerate bile salts and stomach acidity. These microorganisms can be a part of the gut microflora with ability to bind to intestinal cells in competition with pathogen microorganisms. They can produce antimicrobial compounds such as lactic acid, and bacteriocin etc. (1). The term of probiotic is derived from Greek language meaning life. According to the latest report of the Food and Agriculture Organization (FAO) and World Health Organization (WHO), probiotics are live microorganisms whose adequate intake causes beneficial effects on health (2). Several studies demonstrated their effects on prevention and treatment of many diseases (1). Intestinal microflora is very dependent on consumed food type. Therefore, it can substitute harmful microorganisms with useful types. Probiotics promote the growth of beneficial intestinal bacteria or reduce harmful microorganisms (3). Diarrhea is one of the causes of children's illness, and mortality in developing countries. After viruses, bacteria are the second causative agents in diarrhea. Almost $30 \%$ of cases are bacterial with high treatment costs, E. coli is one of the main bacteria of intestinal microflora (4). Intestinal pathogenic E. coli causes $8-10 \%$ of diarrhea cases in children (5). Isolation of $E$. coli O157:H7 is more than other enteric pathogens especially Shigella in the United States (6). The Enterohemorrhagic

\section{Corresponding author:}

Dr. Leila Mahmoodnia, Department of Internal Medicine, Shahrekord University of Medical Sciences, Shahrekord, Iran. Tel: +989131849752, Fax: +983813330709, Email: leilamahmoodnia@yahoo.com

Received: August 18, 2016, Accepted: Janaury 05, 2017, Published: March 2018

iThenticate screening: November 12, 2016, English editing: March 27, 2017, Quality control: February 15, 2018

(C) 2018 The Authors. This is an open access article under the terms of the Creative Commons Attribution-NonCommercialNoDerivs License, which permits use and distribution in any medium, provided the original work is properly cited, the use is non-commercial and no modifications or adaptations are made. 
Escherichia coli (EHEC) strains are discussed as causative agents of hemorrhagic colitis and hemolytic uremic syndrome. Shiga-like toxin of this strain has verotoxic effects. Infective dose of E. coli O157:H7 is low and up to 100 bacteria causing disease (7). Recently, unprecedented outbreaks of E. coli O157:H7 infection happened in Japan, Scotland and America and with other serotypes of EHEC in Europe and Australia, it seems, further investigation in applying new techniques to prevent and control these bacteria are necessary (8). In developing countries, as a major public health problem the main cause of diarrhea among children is Escherichia coli bacteria (9). Nowadays, probiotics are consumed to inhibit pathogens and increase shelf life of foods. They release antimicrobial compounds (such as lactic acid, bacteriocin and hydrogen peroxide) and compete with pathogens that lead to increase the immune response of the host (1). Incidence of antibiotic resistance, loss of normal intestinal flora, verotoxin induced by $E$. coli strains particularly as a result of taking antibiotics, needs novel therapeutic methods (10). The aim of this study was to determine the antimicrobial effect of different isolated probiotics against E. coli O157:H7 and pathogenic EHEC strains using two disk diffusion and well diffusion methods.

\section{Material and Methods}

\subsection{Isolation and identification of bacteria}

For separation of probiotic bacteria, 20 samples of traditional dairy products including (yogurt, cheese and milk) and 20 samples of vegetables including carrots and cabbages (red and white) were collected from different areas of Ahvaz city as well as 10 samples of Tarkhineh (traditional food rich of variety of specific probiotics) that were collected from Khorramabad (West of Iran). MRS Broth and MRS Agar mediums (Merck, Germany) were used for their separation of prepared samples. At first 1 gr of each sample (dairy, vegetables, Tarkhineh) (carrots and cabbage samples were crushed in a sterile mortar) were weighed, dissolved in $10 \mathrm{ml}$ MRS Broth medium then incubated at $37{ }^{\circ} \mathrm{C}$ and shaken at $140 \mathrm{rpm}$ for 24 hours (8). Serial dilution was prepared (to 10-3) and further purification was performed under sterile conditions by culturing in MRS Agar medium. All isolated colonies were identified using biochemical tests (gram staining, catalase test, oxidase test, growth at different temperatures and carbohydrates fermentations and motility) and molecular assessment (polymerase chain reaction test) (11). General primers capable proliferations of 16 rRNA genes were used to perform PCR test (Takapoozist, Iran). Primer's sequencing was shown in Table 1. To confirm genome replication and determine fragment size, PCR protocol was followed on agarose gel. Gel extraction kit was used for extraction 1500-bp single bands. To determine sequencing, purified genes were sent to Takapoozist Company. The results were arranged using BioEdit software and were evaluated in the National Center for Biotechnology Information (NCBI) website using Blast software. Phylogenetic trees of identified isolates were drawn using mega-4 software.

Table 1. Selected primers for polymerase chain reaction

\begin{tabular}{|l|l|l|}
\hline Primers type & Primers sequences (5' to 3') & Product size (bp) \\
\hline Forward primer (FP1) & 5'- AGAGTTTGATCATGGCTCAG-3' $^{\prime}$ & 20 bases \\
\hline Reverse primer (RP1) & 5'-TACGGYTACCTTGTTACGACTT-3' $^{\prime} 22$ bases \\
\hline
\end{tabular}

\subsection{Supernatant preparing of bacteria}

After isolation and molecular identification of isolates, 5 strains of probiotic bacteria were selected, randomly. All selected isolates were cultured in MRS Broth and incubated at $37^{\circ} \mathrm{C}$ for 24 hours to obtain $0.5 \mathrm{McFarland}$ turbidity $\left(1.5 \times 10^{8} \mathrm{cfu} / \mathrm{ml}\right)$. Bacterial supernatant was prepared by centrifuge of isolates culture suspension for $25 \mathrm{~min}$ at $4{ }^{\circ} \mathrm{C}$ and $3500 \mathrm{rpm}$.

\subsection{Preparation of pathogenic bacteria}

Two pathogenic strains of E. coli including EHEC (Enterohemorrhagic E. coli) and E. coli O157:H7 strains were provided by the microbiology department of Tarbiat Modares University in Tehran. TSB medium was used for culturing strains at $37^{\circ} \mathrm{C}$.

\subsection{Evaluation of antimicrobial activity of probiotic bacteria}

Mueller-Hinton Agar (MHA) was used to investigate antimicrobial activity of isolated probiotic bacteria. For this purpose, inhibitory and antagonistic effects of probiotic bacteria on 2 pathotype of $E$. coli was determined using two methods: Disk Diffusion Agar and Well Diffusion Agar methods. All tests were repeated twice.

2.4.1. Disk Diffusion Agar method:

Sterile blank disks ( $8 \mathrm{~mm}$ diameter) were smeared with supernatant of 5 probiotic bacteria for 5 minutes. In order to dry them, all disks were placed at $37^{\circ} \mathrm{C}$ for 15 minutes. The suspension of pathogenic bacteria was spread on plates containing MHA medium. Impregnated discs with supernatant were placed on MHA with a $2.5 \mathrm{~cm}$ distance. All 
http://www.ephysician.ir

plates were incubated at $37^{\circ} \mathrm{C}$ and after 24 hours, growth inhibition zone of probiotics against pathotypes of $E$. coli were measured by a ruler.

2.4.2. Well Diffusion Agar method:

Suspension of pathogen bacteria cultured in TSB were spread on plates containing MHA, then $10 \mu$ of each probiotic supernatant was spilled to punch wells in the plates. After incubation at $37{ }^{\circ} \mathrm{C}$ for 24 hours, growth inhibition zone was measured (12). In comparison, antimicrobial effects of 5 antibiotics on 4 pathotype E. coli were investigated including: nalidixic acid, penicillin, cephalosporin, gentamicin and novobiocin. For this purpose, the suspension of pathogenic bacteria was spread on TSA plates and antibiotic discs were placed with a distance (2.5 $\mathrm{cm}$ ) on them. After incubation at $37^{\circ} \mathrm{C}$ for 24 hours, growth inhibition zone was measured with a ruler.

\section{Results}

A total of 13 probiotic colonies isolated from samples of which, 5 isolates were selected to evaluate the antimicrobial effect against $4 \mathrm{E}$. coli pathotypes, randomly, that were subjected to biochemical and molecular identification. Identified probiotics strains were Lactobacillus plantarum, Lactobacillus Gasseri, Enterococcus faecium, Bacillus subtilis, Weissella paramesenteroides. Obtained results showed growth inhibition effects of all 5 probiotic strains on E. coli O157:H7 in both used methods. Growth inhibition zone was not seen against EHEC Pathotype in both methods. Mean growth inhibition zone of 5 probiotic strain against E. coli O157:H7 pathotype in disk diffusion and well diffusion methods were $9-12 \mathrm{~mm}$ and 6-9 $\mathrm{mm}$, respectively. In comparison, inhibition zones in disk diffusion were considerable. Results of growth inhibition zone of two disk diffusion and well diffusion methods were shown in Tables 2 and 3, respectively. Among five probiotic strains, Lactobacillus plantarum and Weissella paramesenteroides created growth inhibition zone in both methods against E. coli O157:H7 strain (Figure 1). Table 4 shows growth inhibition zone of used antibiotics against two pathotypes. Obtained results showed that nalidixic acid antibiotic had a significant inhibitory effect on both pathotypes EHEC $(20 \mathrm{~mm})$ and O157:H7 (22 $\mathrm{mm}$ ) (Figure 1).

Table 2. Growth Inhibition zone $(\mathrm{mm})$ of selected probiotic strains against 2 pathotypes of E. coli (Disk diffusion method)

\begin{tabular}{|l|l|l|}
\hline \multirow{2}{*}{ Probiotic } & \multicolumn{2}{|l|}{ Pathogen } \\
\cline { 2 - 3 } & O157:H7 & EHEC \\
\hline L.plantarum & 9 & - \\
\hline L.gasseri & 9 & - \\
\hline E. fascium & 9 & - \\
\hline B. subtilis & 12 & - \\
\hline W. paramesenteroides & 10 & - \\
\hline
\end{tabular}

Table 3. Growth Inhibition zone ( $\mathrm{mm}$ ) of selected probiotic strains against 2 pathotypes of $E$. coli (well diffusion method)

\begin{tabular}{|l|l|l|}
\hline \multirow{2}{*}{ Probiotic } & \multicolumn{2}{|l|}{ Pathogen } \\
\cline { 2 - 3 } & O157:H7 & EHEC \\
\hline L.plantarum & 6 & - \\
\hline L.gasseri & - & - \\
\hline E. fascium & - & - \\
\hline B. subtilis & - & - \\
\hline W. paramesenteroides & 9 & - \\
\hline
\end{tabular}

Table 4. Growth inhibitory zone of selected antibiotics against 2 pathotypes of E. coli (Antibiogram)

\begin{tabular}{|l|l|l|}
\hline \multirow{2}{*}{ Antibiotic } & \multicolumn{2}{|l|}{ Pathogen } \\
\cline { 2 - 3 } & O157:H7 & EHEC \\
\hline Nevobiocin & - & - \\
\hline Penicillin & - & - \\
\hline Nalidixic acid & 22 & 20 \\
\hline Cephalosporins & - & - \\
\hline Gentamycin & - & - \\
\hline
\end{tabular}




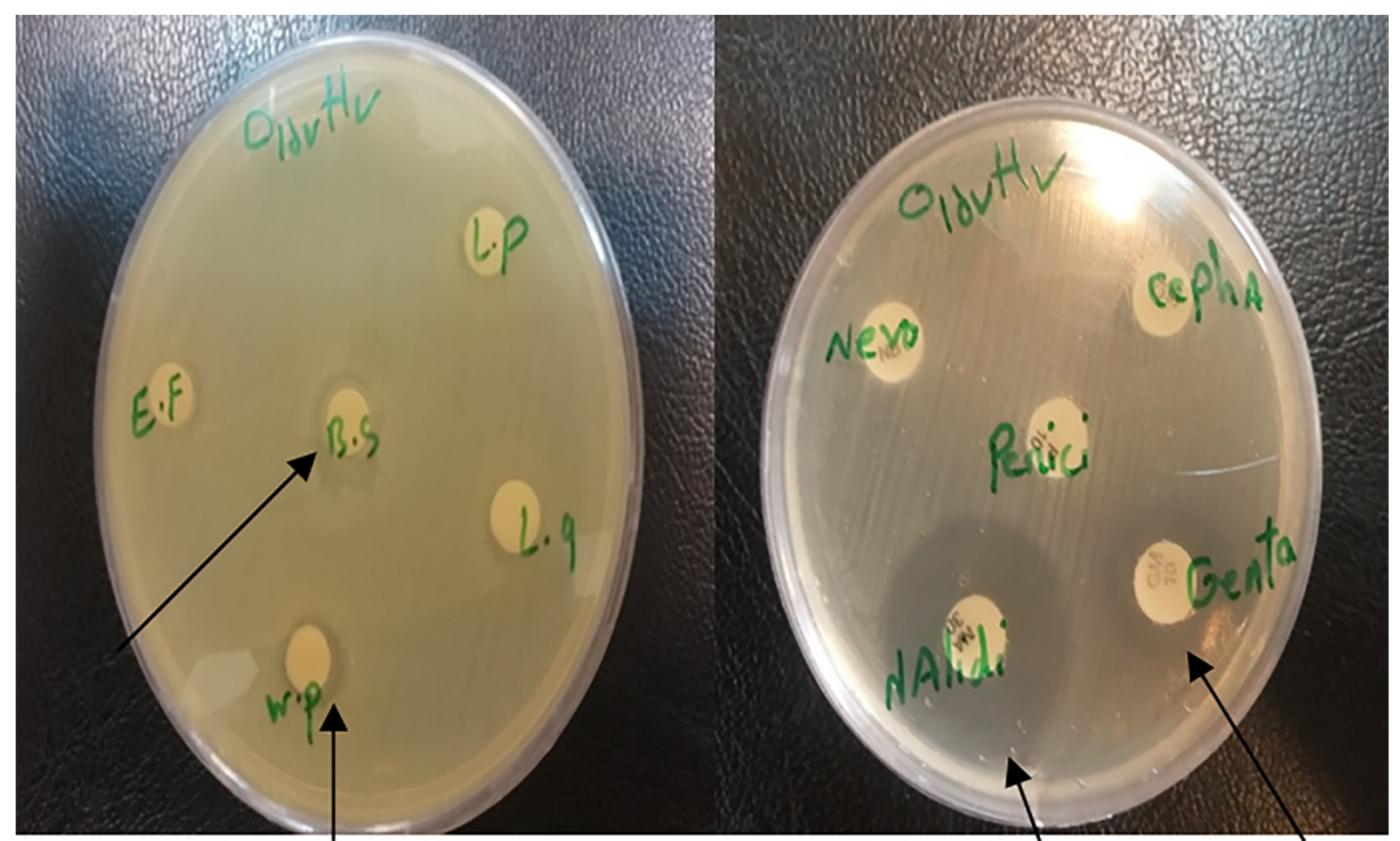

Figure 1. Left: inhibition zone on the strain O157:H7 in disc method; Right: inhibition zone on the strain O157:H7 by antibiotic discs

\section{Discussion and conclusions}

Selected probiotics particularly Lactobacillus plantarum and Weissella paramesenteroides had good inhibitory effects against E. coli $\mathrm{O} 157: \mathrm{H} 7$ pathotype. Probiotics had no inhibitory effect on the EHEC strain. Infectious diarrhea diseases are characterized as the second cause of death in children younger than 5 years among infectious diseases (13). Approximately one billion cases of diarrhea occur in children younger than 5 years, annually, of which around 4.5 million lose their lives. Many studies have been conducted to evaluate pathogens causing diarrhea, as well as innovative and effective treatment methods worldwide. Comparing the results, shows variable incidences in different regions. Acute infectious diarrhea is the fifth cause of death and $16.2 \%$ of infectious diseases in Iran (14). The fifth cause of acute infectious diarrhea that can lead to death due to infectious diseases in Iran accounted for 16.2 percent of the data (18). Causes of diarrheal diseases are varied between developing and developed countries, considerably -in range. Viruses are important agents of diarrheal diseases in developed countries, while bacterial agents such as ETEC, Campylobacter species, Shigella and Salmonella spp are causing agents in most developing countries $(15,16)$. Diarrheagenic $E$. coli is known as the most important causative agent of endemic and epidemic diarrhea in the world (17). Zeighami et al. and Pourakbari et al. recorded that EHEC strain is the causative agent in $12.1 \%$ and $17 \%$ of diarrheal diseases in children younger than 5 years, respectively $(18,19)$. Erdogan et al. in Turkey, reported E. coli O157:H7 in 1\% of diarrheal patients (10). Many studies showed growth inhibitory effects of probiotics against different pathogens, Ota et al. reported that yogurt consumption causes intestinal colonization of probiotic bacteria such as Lactobacillus, and provided conditions to prevent colonization of EHEC. They observed that different lactobacilli culture supernatant can prevent growth of different pathogens such as Listeria monocytogenes, Salmonella, Shigella and Staphylococcus aureus (20). Hassanzadazar et al. showed growth inhibitory effects of probiotic Lactobacillus casei and Enterococcus fascium against Listeria monocytogenesis, Escherichia coli bacillus cereus and Salmonella enteritidis $(21,22)$. Obtained results of the present study showed growth inhibitory effects of 5 probiotic bacteria against E. coli O157:H7 strain. Similar studies confirmed antimicrobial effects of culture supernatant of probiotics, for example Hirano et al showed growth inhibitory effects of L. plantarum and Lactobacillus curvatus against different pathogens with well diffusion method (23). Matsusaki studied growth inhibitory effects of probiotic Lactobacillus with colony count method (24). Based on the results of this study, present probiotic bacteria in natural resources can be used for inhibition and reduction of pathogens, including enteric pathogens and antibacterial effects of their metabolites are active and stable under different conditions of temperature and acidity. 


\section{Acknowledgments:}

We are thankful to the staff and experts at the Microbiology Laboratory of Veterinary Medicine, Lorestan University who helped in conducting parts of this research.

\section{Conflict of Interest:}

There is no conflict of interest to be declared.

Authors' contributions:

All authors contributed to this project and article equally. All authors read and approved the final manuscript.

\section{References:}

1) Soccol CR, Vandenberghe LP, Spier MR, Medeiros AB, Yamaguishi CT, Lindner JD, et al. The potential of probiotics: a review. Food Technology and Biotechnology. 2010; 48(4): 413-34.

2) Anandharaj M, Sivasankari B, Parveen Rani R. Effects of probiotics, prebiotics, and synbiotics on hypercholesterolemia: a review. Chinese Journal of Biology. 2014; 2014(1): 7. doi: 10.1155/2014/572754.

3) Torkan S, Shirani D, Rahimi E, Ghomi K. The Evaluation of Probiotic Effect on Prevention of Food Bacterial Poisoning in Dog. J of Comparative Pathobiology. 2011; 8(1): 403-13.

4) Taniuchi M, Walters CC, Gratz J, Maro A, Kumburu H, Serichantalergs O, et al. Development of a multiplex polymerase chain reaction assay for diarrheagenic Escherichia coli and Shigella spp. and its evaluation on colonies, culture broths, and stool. Diagn Microbiol Infect Dis. 2012; 73(2): 121-8. doi: 10.1016/j.diagmicrobio.2012.03.008. PMID: 22541788.

5) Nahaei MR, Akbari Dibavar M, Sadeghi J, Nikvash S. Frequency of enterohaemorrhagic Escherichia coliisolated from patients with acute diarrhea in Tabriz hospitals. Iran J Med Microbiol. 2007; 1(3): 39-46.

6) Center for Disease Control. Escherichia coli O157: H7, 2001.

7) Combs BG, Raupach JC, Kirk MD. Surveillance of Shiga toxigenic Escherichia coli in Australia. Commun Dis Intell Q Rep. 2005; 29(4): 366-9. PMID: 16465925.

8) Sieladie DV, Zambou F, Kaktcham PM, Cresci A, Fonteh F. Probiotic properties of lactobacilli strains isolated from raw cow milk in the western highlands of Cameroon. Innovative Romanian Food Biotechnology. 2011; 9: 12 .

9) Nataro JP, Mai V, Johnson J, Blackwelder WC, Heimer R, Tirrell S, et al. Diarrheagenic escherichia coli infection in Baltimore, Maryland, and New haven, Connecticut. Clin Infect Dis. 2006; 43(4): 402-7. doi: 10.1086/505867. PMID: 16838226.

10) Erdoğan H, Levent B, Erdoğan A, Güleșen R, Arslan H. [Investigation of verotoxigenic Escherichia coli O157: H7 incidence in gastroenteritis patients]. Mikrobiyol Bul. 2011; 45(3): 519-25. PMID: 21935785.

11) Salaj R, Štofilová J, Šoltesová A, Hertelyová Z, Hijová E, Bertková I, et al. The effects of two Lactobacillus plantarum strains on rat lipid metabolism receiving a high fat diet. The Scientific World Journal. 2013; 2013(1): 7. doi: 10.1155/2013/135142.

12) Darsanak KR, Ghaemi N, Mirdavoodi F. Anti-mutation activity of probiotic strains isolated from probiotic products. J of Qom Uni of Med Sci. 2012; 6(2): 37-44.

13) Alikhani MY, Mirsalehian A, Fatollahzadeh B, Pourshafie MR, Aslani MM. Prevalence of enteropathogenic and Shiga toxin-producing Escherichia coli among children with and without diarrhoea in Iran. J Health Popul Nutr. 2007; 25(1): 88-93. doi: 10.1016/s0924-8579(07)72044-7. PMID: 17615908, PMCID: PMC3013268.

14) Enayat K, Fariborz S, Heiman S, Mehdi SD. Frequency, antimicrobial susceptibility and plasmid profiles of Escherichia coli pathotypes obtained from children with acute diarrhea. Jundishapur Journal of Microbiology. 2011; 4(1): 23-8.

15) Jertborn M, Svennerholm AM. Enterotoxin-producing bacteria isolated from Swedish travellers with diarrhoea. Scand J Infect Dis. 1991; 23(4): 473-9. doi: 10.3109/00365549109075096. PMID: 1957131.

16) Baudry B, Savarino SJ, Vial P, Kaper JB, Levine MM. A sensitive and specific DNA probe to identify enteroaggregative Escherichia coli, a recently discovered diarrheal pathogen. J Infect Dis. 1990; 161(6): 1249-51. doi: 10.1093/infdis/161.6.1249. PMID: 2189007.

17) Sarshar M, Tavafi H, Ghorbani DS, Sood N, Kargar M, Shahrokhi N. Antibiotic resistance to tetracycline resistance genes in strains of E. coli and distribution diarrhea isolated from children. Iranian Journal of Infectious Diseases. 2012; 17(57): 13-8. 
18) Zeighami H, Haghi F, Hajiahmadi F, Kashefiyeh M, Memariani M. Multi-drug-resistant enterotoxigenic and enterohemorrhagic Escherichia coli isolated from children with diarrhea. J Chemother. 2014; 27(3): 152-5. doi: 10.1179/1973947813Y.0000000161. PMID: 24571245.

19) Pourakbari B, Heydari H, Mahmoudi S, Sabouni F, Teymuri M, Ferdosian F, et al. Diarrhoeagenic E. coli pathotypes in children with and without diarrhoea in an Iranian referral paediatrics centre. East Mediterr Health J. 2013; 19(7): 617-21. PMID: 24975306.

20) Kargar M, Homayon M, Yaghoubi R, Manokianis A. Pathogenic gene stx1, stx2, eaeA and hly with Multiplex PCR in strains of E. coli O157: H7 isolated from children with acute gastroenteritis in the city of Shiraz. Iranian Journal of Infectious Diseases. 2009; 14(44): 7-12.

21) Hassanzadazar H, Ehsani A, Mardani K. Antibacterial activity of Enterococcus faecium derived from Koopeh cheese against Listeria monocytogenes in probiotic ultra-filtrated cheese. Vet Res Forum. 2014; 5(3): 169-75. PMID: 25568714, PMCID: PMC4279643.

22) Hassanzadazar H, Ehsani A, Mardani K, Hesari J. Investigation of antibacterial, acid and bile tolerance properties of lactobacilli isolated from Koozeh cheese. Vet Res Forum. 2012; 3(3): 181-5. PMID: 25610566, PMCID: PMC4299980.

23) Mehrabian S, Tahmasbi H, Momtaz H, Farahmandi SH, Davoodi JH. Find carrying E. coli Shiga toxin genes of Multiplex Polymerase Chain Reaction method for Escherichia coli isolated from patients with acute diarrhea referred to Hajar hospital. 2012; 18(21): 8-14.

24) Lotfalie Haghighi. Intestinal bacteria (Enterobacteriaceae family). Press start treatment Bushehr University of Medical Sciences. 2004; 10-20. 